\title{
In-Bed Accountability of Tritium in Production Scale Metal Hydride Storage Beds (U)
}

by

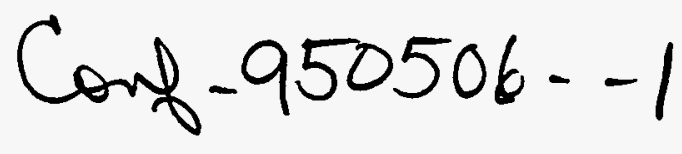

J. E. Klein

Westinghouse Savannah River Company

Savannah River Site

Aiken, South Carolina 29808

\section{DISCLAIMER}

This report was prepared as an account of work sponsored by an agency of the United States Government. Neither the United States Government nor any agency thereof, nor any of their employees, makes any warranty, express or implied, or assumes any legal liability or responsibility for the accuracy, completeness, or usefulness of any information, apparatus, product, or process disclosed, or represents that its use would not infringe privately owned rights. Reference herein to any specific commercial product, process, or service by trade name, trademark, manufacturer, or otherwise does not necessarily constitute or imply its endorsement, recommendation, or favoring by the United States Government or any agency thereof. The views and opinions of authors expressed herein do not necessarily state or reflect those of the United States Government or any agency thereof.

\section{MASTER}

A document prepared for FIFTH TOPICAL MEETING ON TRITIUM TECHNOLOGY IN FISSION, FUSION AND ISOTOPIC APPLICATIONS at Belgirate, Lake Maggiore from 05/28/95 - 06/03/95.

DOE Contract No. DE-AC09-89SR18035

This paper was prepared in connection with work done under the above contract number with the U.S. Department of Energy. By acceptance of this paper, the publisher and/or recipient acknowledges the U.S. Government's right to retain a nonexclusive, royalty-free license in and to any copyright covering this paper, along with the right to reproduce and to authorize others to reproduce all or part of the copyrighted paper. 


\title{
DISCLAIMER
}

\begin{abstract}
Portions of this document may be illegible in electronic image products. Images are produced from the best available original document.
\end{abstract}




\section{DISCLAIMER}

This report was prepared as an account of work sponsored by an agency of the United States Government. Neither the United States Government nor any agency thereof, nor any of their employees, makes any warranty, express or implied, or assumes any legal liability or responsibility for the accuracy, completeness, or usefulness of any information, apparatus, product, or process disclosed, or represents that its use would not infringe privately owned rights. Reference herein to any specific commercial product, process, or service by trade name, trademark, manufacturer, or otherwise does not necessarily constitute or imply its endorsement, recommendation, or favoring by the United States Government or any agency thereof. The views and opinions of authors expressed herein do not necessarily state or reflect those of the United States Government or any agency thereof.

This report has been reproduced directly from the best available copy.

Available to DOE and DOE contractors from the Office of Scientific and Technical Information, P.O. Box 62, Oak Ridge, TN 37831; prices available from (615) 576-8401.

Available to the public from the National Technical Information Service, U.S. Department of Commerce, 5285 Port Royal Road, Springfield, VA 22161. 
IN-BED ACCOUNTABILITY OF TRITIUM IN PRODUCTION SCALE METAL HYDRIDE STORAGE BEDS

J. E. Klein

\author{
Westinghouse Savannah River Company \\ Savannah River Site \\ Aiken, SC 29808, U.S.A.
}

\section{ABSTRACT}

An "in-bed accountability" (IBA) flowing gas calorimetric measurement method has been developed and implemented to eliminate the need to remove tritium from production scale metal hydride storage beds for inventory measurement purposes. Six-point tritium IBA calibration curves have been completed for two, 390 gram tritium metal hydride storage beds. The calibration curves for the two tritium beds are similar to those obtained from the "cold" test program. Tritium inventory errors at the 95 percent confidence level ranged from \pm 7.3 to 8.6 grams for the cold test results compared to \pm 4.2 to 7.5 grams obtained for the two tritium calibrated beds.

\section{INTRODUCTION}

Start-up of a new tritium handling facility, the Replacement Tritium Facility (RTE), has been recently completed at the Savannah River Site (SRS). In the RTF, metal hydride technology is used to separate, store, pump, and-purify hydrogen isotopes on a production scale. ${ }^{1}$ One disadvantage of hydride storage is in performing the required, periodic physical inventory measurements of the tritium. A unique relationship does not exist between the amount of tritium contained in a metal hydride bed and the pressure-volumetemperature-composition (PVTC) properties of the hydride material. Desorption of tritium to tanks for PVTC measurements is not practical for the RTF hydride storage beds due to the long gas desorption/absorption times and the "trapping" of tritium in the lattice of the $\operatorname{LaNi}_{4.25} \mathrm{Al}_{0.75}$ alloy after radiological exposure to tritium.

To eliminate the need to remove tritium from the storage beds for measurement purposes, an "in-bed accountability" (IBA) flowing gas calorimetric measurement method has been developed. In the IBA method, the steadystate temperature rise ( $S S \Delta T$ ) of a gas stream flowing through a jacketed metal hydride storage bed is measured and correlated with the radiolytic power generated by the decay of tritium to He-3. The tritium inventory calibration curve, the correlation between $S S \Delta T$ and bed tritium loading, is generated for each bed and is then used for tritium inventory measurements.
Bed loading will be expressed as the atomic ratio of tritium atoms per atom of metal in the hydride and will be represented as $T / M$. $T / M$ will not only represent actual $T$-over-M ratios, but will also represent simulated tritium-to-metal atomic ratios measured during the cold tests using electric heaters.

This IBA inventory measurement technique has been described previously and has been demonstrated using helium and protium in full-scale prototype hydride beds fitted with electric heaters to simulate the performance of the tritium storage beds. ${ }^{2}$ How "cold" test results were used to implement the IBA method in the RTF will be presented along with the IBA calibration results obtained for two, 390 gram tritium metal hydride storage beds. statistical estimates of the IBA inventory accuracy will also be presented.

\section{BACKGROUND}

\section{Previous Results}

Some results from the cold development program have been presented before. ${ }^{2}$ In that work, five SS $\triangle T$ IBA calibration versus $T / M$ data sets for cold test "Bed 1 " (CB \#1) where presented. One set of data were obtained using helium at $101 \mathrm{kPa}$ ( $1 \mathrm{~atm}$ ) in - the bed at an IBA gas flow rate of 70 standard liters per minute (SLPM) while the other four sets were obtained using protium in the bed at flows of 50,60, 70, and 80 SIPM. Standard temperature and pressure (STP) for these flows were $21.1^{\circ} \mathrm{C}\left(70^{\circ} \mathrm{F}\right)$ and $101 \mathrm{kPa}(1 \mathrm{~atm})$ and were $0^{\circ} \mathrm{C}\left(32^{\circ} \mathrm{F}\right)$ and 101 $\mathrm{kPa}$ for the tritium bed flow instruments. To compare results obtained with different STP reference states, cold test flow rates were converted to flows using the tritium bed instrumentation STP references. Cold test flow rates changed from 50, 60, 70, and 80 SLPM to $46.4,55.7,65.0$, and 74.3 SLPM, respectively. Future STP references will be to $0^{\circ} \mathrm{C}\left(32^{\circ} \mathrm{F}\right)$ and $101 \mathrm{kPa}$.

A linear model was fit to the nine point helium data set over the range of 0 to 0.8 $T / M$. The accuracy of the IBA method was expressed as the inverse regression standard deviation, $\sigma_{\text {inv }}$, for this linear model which 
was $0.0054 \mathrm{~T} / \mathrm{M}$. The reported 95 percent confidence interval accuracy was approximated as two times $\sigma_{\mathrm{inv}}$ and was reported as $\pm 0.011 \mathrm{~T} / \mathrm{M}$ (6.07 grams tritium).2 For a full metal hydride storage bed, given as a tritium loading of $T / M$ equal 0.7 , the accuracy of the IBA technique was stated to be \pm 1.6 percent of a fully loaded bed.2

\section{Further Analysis of Cold Test Data}

Additional data regressions were performed on the $C B \# 1$ data sets. These IBA data sets where reduced to nine points each at nominal loadings of $0,0.05,0.1,0.2$, $0.3,0.4,0.5,0.6$, and $0.7 \mathrm{~T} / \mathrm{M}$. The independence of the IBA calibration data with-respect-to using helium or protium in the bed over the range of 0 to $0.7 \mathrm{~T} / \mathrm{M}$, at 65.0 SLPM, has been established and the method used to make this determination is described in Appendix $A$. The analysis shows that a quadratic model without a $y^{-}$ intercept, $\hat{b}_{0}$ forced to be zero, is the statistically significant model to use to represent these data.

Linear regressions were used in the previous analyses ${ }^{2}$ because the heat transfer model developed was linear and inverse regression equations were available. ${ }^{3}$ To obtain smaller tritium inventory errors for the IBA technique, the relevance of applying quadratic models to the IBA calibration data was investigated. To do this, inverse regression error equations were needed for this model. The author was unable to find these equations in the literature, so the equations derived for this model are summarized in Appendix B. A commercial statistical software package ${ }^{4}$ was used to obtain regression coefficients and variances for use in these equations.

Iinear and quadratic regressions, with and without the $\hat{b}_{0}$ term, were performed on the four, nine-point protium IBA calibration data sets to select the "best" regression models to represent the data. The best regression model was defined as the model with the smallest "standard error of the estimate" 4 in which all regression coefficients were statistically significant. All references to statistical significance will be made at the 95 percent confidence level.

Linear regressions of the nine-point, protium IBA data sets showed that $\hat{b}_{0}$ was not significantly different from zero for any of the regressions. Quadratic regressions showed that $\hat{b}_{0}$ is statistically different from zero for the 46.4 and 55.7 SLPM data, but not for the 65.0 and 74.3 SLPM data. The constants $\hat{b}_{1}$ and $\hat{b}_{2}$ were statistically significant for all quadratic regressions of the protium data sets.
Estimation of Calibration Points

Required

Originally, nine tritium IBA calibration points were to be collected at the previously listed $T / M$ values. To reduce the number of calibration data points (N) needed for IBA calibrations of the tritium beds, the relationship between IBA inverse regression accuracy and $\mathrm{N}$ was determined. The inverse regression error was expressed as the confidence interval " $t$ " times $\sigma_{\text {imv }}$ $\left(t * \sigma_{\text {inv }}\right)$ where $t$ is the student's $t$ value taken from standard tables ${ }^{s}$ and $\sigma_{\text {inv }}$ was calculated using the equations in Appendix $B$. The maximum value of $\sigma_{\mathrm{ivv}}$ in the range 0 to $0.7 \mathrm{~T} / \mathrm{M}$ was used for calculating this error.

Regression analyses were performed on subsets of the nine point, 65.0 SLPM protium data set with each subsets chosen in an attempt to evenly space-out the calibration data over the entire $T / M$ range. Data regressions showed that for $N$ less than six, the linear model without $\hat{b}_{0}$ was the statistically significant model, but for $N \geq$ 6 , the quadratic model without $\hat{b}_{0}$ was the statistically significant model.

The correlation between IBA accuracy and $N$ is shown in Figure 1. For $N$ less than five, the linear model without $\hat{b}_{0}$ results are shown and for $N \geq 6$, the quadratic model without $\hat{b}_{0}$ results are shown. Based on the results of this analysis, six calibration points were selected for IBA calibration of the tritium storage beds since $N$ greater than six did not significantly decrease the IBA measurement error. The estimated accuracy of the IBA technique for $N$ equal 6 was $\pm 0.0123 \mathrm{~T} / \mathrm{M}$ (6.85 grams of tritium) which is slightly higher than the previously stated value of $\pm 0.011 \mathrm{~T} / \mathrm{M}$.

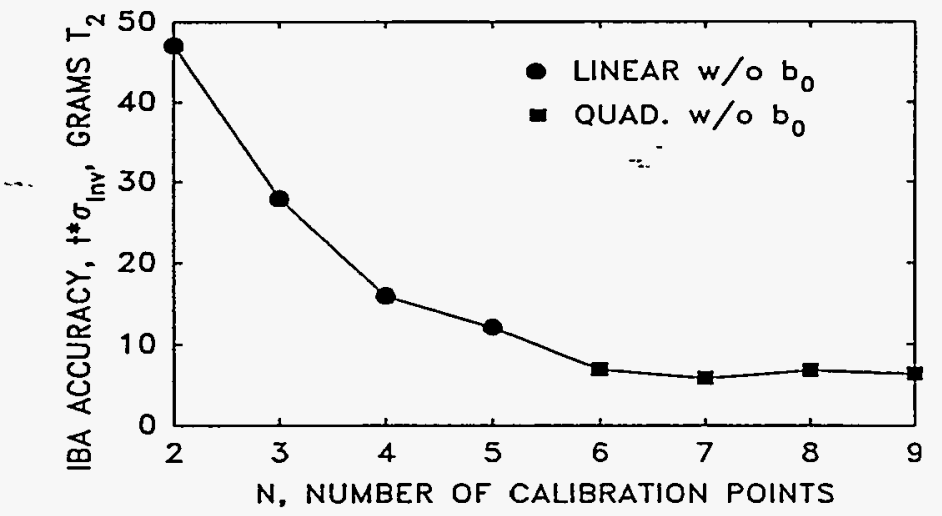

Figure 1. Cold Data IBA Error Versus $N$

Data regressions were also performed on subsets of the other protium data sets. all cases, $\hat{b}_{0}$ was not statistically significant for any of the linear regressions. For the quadratic regressions, the statistical significance of $\hat{b}_{0}$ and $\hat{b}_{2}$ for different values of $\mathrm{N}$ varied. In general, the trend was a linear model without $\hat{b}_{0}$ would
In - 
be selected for lower values of $\mathrm{N}$ and a quadratic model, with or without $\hat{b}_{0}$, would be selected for larger values of $N$. Regression errors obtained at IBA flows other than 65.0 SLPM were greater than or similar to the errors obtained for the 65.0 SLPM flow so no further analyses was performed on these data.

\section{PVTC Accuracy of Tank Transfers}

The amount of tritium contained in a bed during IBA calibrations was calculated using PVTC measurements on a calibrated tank. A site policy states a calibrating device shall have an uncertainty one-fourth, or less, than the item being calibrated. This "4-to-1" calibration criteria requires tritium measurement errors for calibrated tank/bed transfers must be less than the one-fourth the IBA measurement error. The cold test IBA accuracy of $\pm 0.0123 \mathrm{~T} / \mathrm{M}$ at $\mathrm{N}$ equal six was used to see if this criteria was met.

Mass balance equations using the ideal gas law were derived to calculate the amount and accuracy of PVTC tritium tank/bed transfers. A random error propagation analysis was applied to this equation with independent, random errors assigned to each of the PVTC parameters. The calculated error propagation variance for each gas transfer was summed to calculate the over-all error in the PVTC calculations.

The sequence for the PVTC error calculations was to start with an evacuated bed, load the bed to the highest $T / M$ loading first and then remove portions of that gas to obtain the other target bed calibration loadings. Estimates were made for tank temperatures, gas tritium mole fractions, and the tank volume. Independent parameters for performing the calculations were the initial tank pressure before any gas transfer, the lowegt tank pressure allowed before refilling the tank was required, or the tank pressure for desorption of gas from the bed to the tank.

The PVTC error estimates obtained using this calibration procedure and error analysis technique indicated that the 4-to-1 criteria could not be meet with existing equipment and procedures: the initial calibration ratio was approximately 1.1-to-1. To improve this calibration ratio, lower tank pressures were proposed for the tank/bed transfers and a high accuracy pressure transducer error tolerance of $\pm 93 \mathrm{~Pa}(0.7$ torr) was used in the calculations. The changes resulted in an estimated PVTC calibration error ratio of 2.5-to-1. Higher calibration error ratios would have required extensive equipment modifications and thus a waiver to the 4-to-1 criteria was obtained.

\section{EXPERIMENTAL}

A nominal 1500 liter calibrated tank, fitted with two RTDs and a high accuracy pressure transducer, were used for tank/bed transferg for IBA calibrations. Tritium compositions were determined by mass spectrometry of tank gas samples and were specified to be $\geq 90$ volume percent tritium for the tank-to-bed transfer. All PVTC measurements for the calibrated tank were taken after the tank had at least ninety minutes to thermally equilibrate. The process line volume connecting the tank to the hydride bed was calculated by PVT gas expansion from the tank into the evacuated line before the first tritium loading of the bed.

The tritium bed mass flow controllers (MFCs) were calibrated at several flow rates using a NIST calibrated turbine meter installed in-line with the MFC before IBA calibration of the bed. The IBA MFC set point gas flow rate of 70 SLPM was checked before and after each IBA calibration point to verify the accuracy of the instrument and to ensure its flow rate did not drift out of specification ( \pm 2 SLPM) during the calibration.

The tritium storage beds were of similar construction to the cold test beds ${ }^{2}$ with the main difference being the absence of heaterwells installed in the beds. Both tritium beds, denoted TB \#1 and TB \#2, were insulated using the same insulation specification as had been used for the cold test beds except TB \#2 which had an additional layer of insulation installed on the bed. Placement of the RTDs in the IBA gas flow lines leading to and from the beds were of a similar configuration as those used in the cold tests.

In preparation for IBA calibrations, the hydride bed was heated to at least $140^{\circ} \mathrm{C}$ and to a pressure less than $133 \mathrm{~Pa}$ ( 1 torr) for several hours to remove hydrogen isotopes from the bed. Evacuation of the bed was verified by performing a rate-of-rise on the bed and requiring a total pressure of less than $1.33 \mathrm{kPa}$ (10 torr) be obtained in 30 to 60 minutes.

SS $\Delta T$ data were obtained under controlled conditions. Criteria specified were that the difference between the inlet IBA gas temperature and the glovebox temperature be less than or equal to $\pm 2{ }^{\circ} \mathrm{C}$, the IBA gas flow occur for at least four hours, and that the average $\Delta \mathrm{T}$ data for the bed outlet and inlet gas temperatures over a one hour time period be constant and have a small rate of change.

IBA bed calibration data were to be obtained at nominal bed loadings of $0,0.70,0.56$, $0.42,0.28$, and $0.14 \mathrm{~T} / \mathrm{M}$ for $\mathrm{TB} \# 1$. Results from $T B$ \#1 lead to nominal bed loadings of $0,0.60,0.48,0.36,0.24$, and $0.12 \mathrm{~T} / \mathrm{M}$ being selected for TB \#2. The IBA zero point, SS $\Delta T$ data for an evacuated bed ( $T / M$ equal 0), was performed first. Next, a tank-to-bed gas transfer was performed to 
obtain the highest bed loading for IBA calibration. SS. $\Delta T$ conditions were established and these data were collected along with PVTC data. For each subsequent IBA calibration point, a portion of the gas on the bed was transferred to the tank to obtain the next highest IBA bed loading. This process was repeated until data collection was completed for all the bed loadings.

\section{RESULTS}

The calibration curves for the two tritium beds are shown in Figure 2. The CB \#1 results shown in Figure 2 at 70 SLPM were obtained by fitting second order polynomials without $\hat{b}_{0}$ to $C B \# 1$ data at 65.0 and 74.3 SLPM over the range of 0 and $0.7 \mathrm{~T} / \mathrm{M}$ and linearly interpolates the results to obtain the values shown.

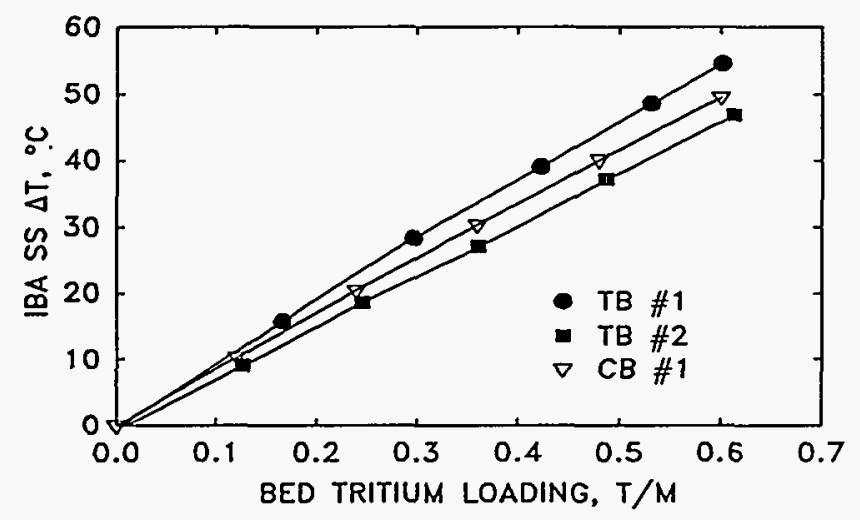

Figure 2. IBA Calibration Curves at 70 SLPM

The IBA calibration curves for TB \#1 and TB \#2 are similar to those obtained for $C B \# 1$. SS $\Delta T$ at $T / M$ equal 0.6 for the bed having more insulation, TB \#1, is approximately $5^{\circ} \mathrm{C}$ higher than that for CB \#1 while for TB \#2, the bed with the same amount of insulation ss $\Delta T$ is approximately $4^{\circ} \mathrm{C}$ lower than $\mathrm{CB} \# 1$. For $T B \# 1$, the quadratic model without $\hat{\mathrm{b}}_{0}$ was the best regression model while for TB \#2, the linear model with $\hat{\mathrm{b}}_{0}$ was the best model.

Two six-point IBA data sets for CB \#1, over the range 0 to $0.6 \mathrm{~T} / \mathrm{M}$, were selected and analyzed to generates statistics which could be compared to the tritium bed IBA

statistics. In the this analysis, the best model for the 65.0 SLPM data changed from quadratic without $\hat{b}_{0}$ to Iinear without $\hat{b}_{0}$. For the 74.3 SIPM calibration data, the quadratic model without $\hat{b}_{0}$ remained the best model. Table 1 shows the IBA inverse regression inventory measurement errors for the two tritium beds and the two $C B \# 1$ data sets using various regression models. The inverse regression error varies slightly with $T / M$ and the maximum values between 0 to $0.6 \mathrm{~T} / \mathrm{M}$ are shown.

Figure 3 shows the hydride temperature at IBA SS $\Delta \mathrm{T}$ conditions versus $\mathrm{T} / \mathrm{M}$ correlation

\begin{tabular}{|c|c|c|c|c|}
\hline \multirow[t]{2}{*}{ Bed } & \multicolumn{4}{|c|}{$\begin{aligned} t * \sigma_{\text {inv }} \text { IBA Inventory Error } \\
\cdot\left(\text { grams } T_{2}\right)\end{aligned}$} \\
\hline & $\begin{array}{c}\text { Linear } \\
\mathbf{w} / \widehat{\mathrm{b}}_{0}\end{array}$ & $\begin{array}{l}\text { Linear } \\
w / 0 \hat{\mathrm{b}}_{0}\end{array}$ & $\begin{array}{l}\text { Quad. } \\
w / \hat{b}_{0}\end{array}$ & $\begin{array}{l}\text { Quad. } \\
\text { w/o } \hat{\mathrm{b}}_{0}\end{array}$ \\
\hline $\begin{aligned} \text { CB } & \# 1 \\
65.0 & \text { SLPM }\end{aligned}$ & $8.98^{\circ}$ & $7.30^{\circ}$ & $8.11^{\circ}$ & $7.68^{\circ}$ \\
\hline $\begin{array}{cl}\text { CB \#1 } \\
74.3 \text { SLPM }\end{array}$ & $13.29^{c}$ & $12.31^{\circ}$ & $7.08^{\circ}$ & $8.60^{\circ}$ \\
\hline $\mathrm{TB} \# 1$ & $15.97^{c}$ & $12.62^{c}$ & $5.98^{c}$ & $7.54^{\mathrm{c}}$ \\
\hline TB \#2 & $4.20^{b}$ & $10.56^{\circ}$ & $6.07^{b}$ & $11.06^{b}$ \\
\hline
\end{tabular}

Minimum values underlined, best model values in bold print.

Maximum error at $0.0 \mathrm{~T} / \mathrm{M}$.

Maximum error at $0.6 \mathrm{~T} / \mathrm{M}$.

Table 1. IBA Errors for Different Models"

to be linear for the cold data while the tritium beds show a quadratic dependence. The difference in temperature relationships for the different beds was attributed to heat conduction along the heaterwells in the cold test prototype beds.

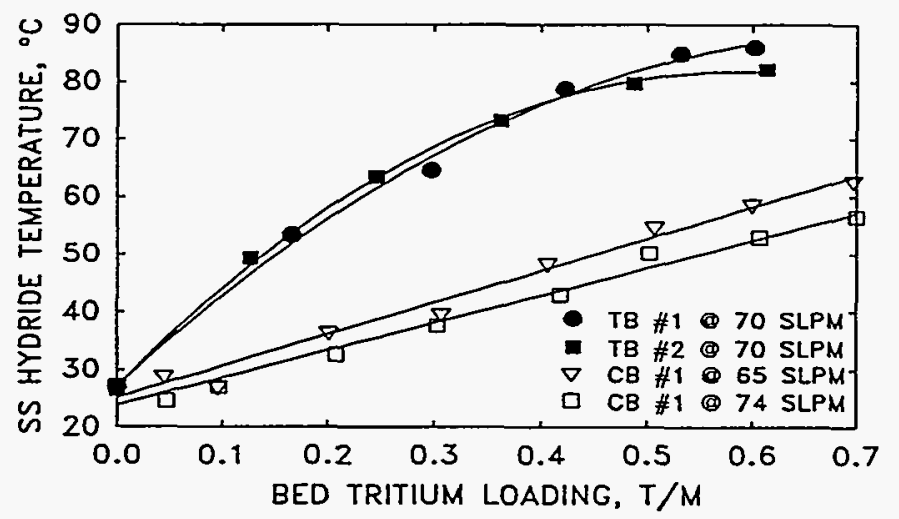

Figure 3. Steady-state IBA Hydride Temperatures

The bed hydrogen isotope pressure at IBA SS $\Delta T$ conditions versus $T / M$ correlation is shown in Figure 4 for the tritium beds and CB \#I at 65.0 SLPM. The solid lines shown in Figure 4 were the results of regressing the logarithm of pressure versus $T / M$ data while the dashed lines show extrapolation of the regression beyond the range of the data.

\section{DISCUSSION}

Iinear models are the easiest to use for regressing and estimating IBA results, but if the best model to for the IBA calibration curve is quadratic, a significant reduction in tritium measurement error can be obtained. The significance of the $\hat{\mathrm{b}}_{0}$ term needs in the model selected needs 


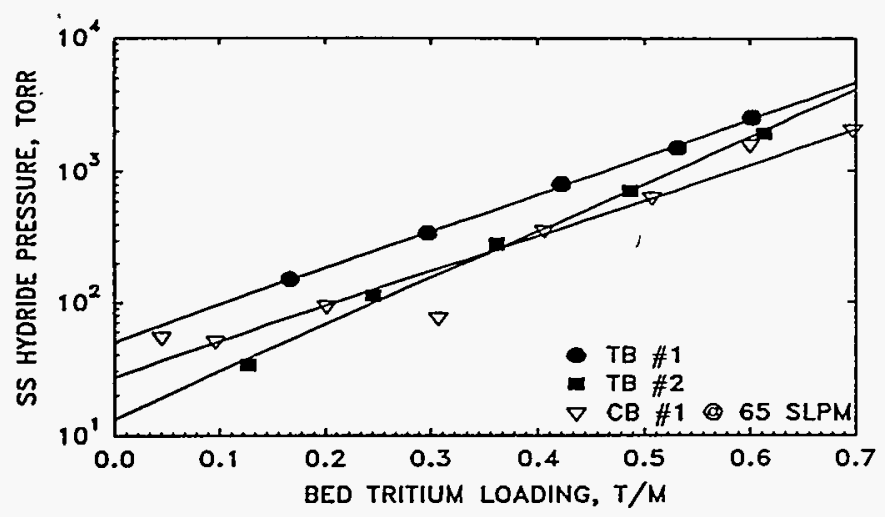

Figure 4. Steady-State IBA Hydride Pressures

to be determined when regression the IBA data. The importance of selecting the best model to calculate IBA tritium inventory errors can be seen from the data in Table 1 . For $\mathrm{CB} \# 1$ at 65.0 SLPM and TB \#2, the linear model with appropriate inclusion/exclusion of $\hat{b}_{0}$ is the best model and also gives the smallest $t * \sigma_{\mathrm{inv}}$ value. Use of a higher order model or the incorrect linear model would produce a larger inventory error than the best model. For $\mathrm{CB} \# 1$ at 74.3 SLPM and TB $\# 1$, the best model is the quadratic model without $\hat{b}_{0}$. Selection of a linear model to represent these data will greatly overestimate the tritium inventory error while selecting the incorrect quadratic model will under-estimate the inventory error. It is interesting to note that IBA on TB \#2 detected less energy than IBA on TB $\# 1$, but TB \#2 had a smaller $t^{*} \sigma_{\text {inv }}$ value.

Figure 3 shows the hydride temperature under IBA SS $\Delta T$ conditions would not be as good a correlation to use as that shown in Figure 2 for tritium inventory measurements. Similar comments can be made of the pressure correlation shown in Figure 4.

The $T / M$ values obtained for the TB \#1 IBA calibration curve shown in Figure 2 were not very close to the target $T / M$ values due to the inability to estimate the quantity of tritium desorbed from the bed during IBA measurements. The pressure correlation shown in Figure 4 was used to make this estimate and the location of the $T / M$ values obtained for the TB $\# 2$ IBA curve were very close to the target values.

\section{CONCLUSIONS}

The results of the cold test program were extremely useful in the development of the IBA technique and in estimating the performance of the tritium production beds. The cold test data gave inventory accuracies gimilar to those obtained for the tritium beds, were useful in determining the number of costly calibration points to perform, and allowed the modification of calibration procedure before testing started to ensure the beds could be calibrated with sufficient accuracy using PVTC transfers.

No general conclusions can be made about which particular regression model should be used for regression IBA data without testing the different order models with and without $\hat{b}_{0}$. Successive testing of the different models can be easily done using a "stepwise" variable selection procedures. ${ }^{4}$ In general, the use of the wrong order polynomial will give a larger inventory error than is attainable. Also, the use of the correct order polynomial, but incorrect

inclusion/exclusion of $\hat{b}_{0}$ in the model can over-estimate, or worse, underestimate the inventory measurement error.

Excellent IBA results were obtained for the two tritium beds with the results similar to that obtained from cold test program. This technique being proven on production scale tritium storage beds demonstrates that large quantities of tritium can be accounted for without removal of the gas from solid storage media. This will prove useful in the design of tritium storage vessel for use in the design of ITER.

\section{ACRNOWLEDGEMENTS}

The author would like to thank $\mathrm{W}$. Troy Elkington, Barb G. Steiner, and Lyndon E. Miller for their assistance in the implementation of the IBA technique into the RTF.

\section{REFERENCES}

1. M. S. ORTMAN, L. K. HEUNG, A. NOBILE, AND R. I. RABUN, Tritium Processing at the Savannah River Site: Present and Future, J. Vac. Sci. Technol., A 8 (3), 2881-2889 (1990).

2. J. E. KLEIN, M. K. MALIORY, AND A. NOBILE, JR., Tritium Measurement Technique Using "In-Bed" Calorimetry, J. Fus. Techn., 2I(2), 401-405 (1992).

3. J. I. JAECH, Statistical Methods in Nuclear Material Control, Technical Information Center, Atomic Energy Commission (1973).

4. Statgraphics $^{\oplus}$ statistical Graphics System, Version 5.0. STSC, Inc., Rockville, MD 20805.

5. N. DRAPER AND H. SMITH, Applied Regression Analysis, Second Edition, John Wiley and Sons, Inc., New York (1981). 
APPENDIX A: INDEPENDENCE OF HELIUM AND HYDROGEN SS $\triangle T$ T.RESUTS AT 65.0 SLPM

The model used to test independence of the helium and hydrogen data was

$$
\hat{Y}=\left(b_{0}+b_{\Delta 0} X_{2}\right)+\left(b_{1}+b_{\Delta 1} X_{2}\right) X_{1}+\left(b_{2}+b_{\Delta 2} X_{2}\right) X_{1}^{2}+e
$$

or

$$
\hat{q}=\hat{b}_{0}+b_{\Delta 0} X_{2}+b_{1} X_{1}+b_{\Delta 1} x_{1} X_{2}+b_{2} x_{1}^{2}+b_{\Delta 2} X_{2} x_{1}^{2}+e
$$

where

$$
\begin{aligned}
& \hat{\mathrm{Y}}=\text { regression estimate of IBA SS } \Delta \mathrm{T} \\
& \text { results, } \\
& \mathrm{x}_{1}=\mathrm{T} / \mathrm{M} \text { data, } \\
& \mathbf{x}_{2} \text { = indicator variable: } 1 \text { for hydrogen } \\
& \text { data, } 0 \text { otherwise, } \\
& \hat{b}_{0}=\text { zeroth order polynomial coefficient } \\
& \text { (intercept) for helium data } \\
& \text { regression, } \\
& \hat{b}_{1}=\text { first order polynomial coefficient } \\
& \text { (slope) for helium data regression, } \\
& \hat{\mathrm{b}}_{2}=\text { second order polynomial coefficient } \\
& \text { for helium data regression, and } \\
& \hat{\mathrm{b}}_{\Delta 0}=\text { difference in intercepts for } \\
& \text { regression of combined helium and } \\
& \text { hydrogen data sets, } \\
& \hat{b}_{\Delta l}=\text { difference in slopes for regression } \\
& \text { of combined helium and hydrogen data } \\
& \hat{b}_{\Delta 2}=\text { difference in second order } \\
& \text { coefficient for regression of } \\
& \text { combined helium and hydrogen data } \\
& \text { sets, and } \\
& \text { e = model error. }
\end{aligned}
$$

To determine if the hydrogen SS $\Delta T$ data were significantly different than helium $\Delta T$ data, the significance of $\hat{\mathrm{b}}_{\Delta 0}, \hat{\mathrm{b}}_{\Delta 1}$, and $\hat{\mathrm{b}}_{\Delta 2}$ in this regression model were checked using regression analysis software. At the $95 \%$ confidence level, the coefficients $\hat{\mathrm{b}}_{\Delta 0}, \hat{\mathrm{b}}_{\Delta \mathrm{l}}$, and $\hat{b}_{\Delta 2}$, and also $\hat{b}_{0}$ were not significantly different from zero. From these results it was concluded that the $S S \Delta T$ versus $T / M$ data at 65.0 SLPM for helium or hydrogen were not significantly different from one another. Furthermore, a second order model with a zero intercept is the statistically significant model to use to represent these data.

APPENDIX B: INVERSE REGRESSION ERROR MODELS

A single variable function, up to second order, is assumed to be of the form

$$
Y=\beta_{0}+\beta_{1} X+\beta_{2} X^{2}+\epsilon
$$

where $X$ is the independent variable, $Y$ is the dependent variable, $\epsilon$ is some error (using the notation of Reference 5), and $\beta_{0}$, $\beta_{1}, \beta_{2}$ are constants. The model used to approximate this function is

$$
\hat{Y}=b_{0}+\sigma_{1} X+\sigma_{2} X^{2}+e
$$

where $e$ is the estimated error which is assumed to be normal with a mean value of zero and estimated standard deviation denoted as $\hat{\sigma}_{e}^{2}$ with $\hat{b}_{0}, \hat{b}_{1}$, and $\hat{b}_{2}$ estimates of $\beta_{0}, \beta_{1}, \beta_{2}$, respectively.

For the inverse-regression, or calibration model, an observed value of $Y, Y_{0}$, is used to obtain the estimated value of $\mathrm{x}, \hat{\mathrm{x}}_{0} \cdot \hat{\mathrm{x}}_{0}$ is calculated, for a linear model, using

$$
\hat{X}_{0}=\left(Y_{0}-b_{0}-e\right) / b_{1}
$$

and for a quadratic model, using

$$
\hat{x}_{0}=\frac{-\hat{b}_{1} \pm \sqrt{\hat{b}_{1}^{2}-4 \hat{b}_{2}\left(\hat{b}_{0}-Y_{0}+e\right)}}{2 \hat{b}_{2}}=\frac{-\hat{b}_{1} \pm \sqrt{R}}{2 \hat{b}_{2}}
$$

where $\mathrm{R}$ is

$$
R=b_{1}^{2}-4 \hat{b}_{2}\left(\hat{b}_{0}-Y_{0}+e\right)
$$

$V()$ is used to denotes the variance of a parameter. The systematic or calibration variance for $\hat{x}_{o}, V_{c}\left(\hat{x}_{0}\right)$, is derived using error propagation. For up to a second order model, $v_{c}\left(\hat{x}_{0}\right)$ is given by

$$
\begin{aligned}
V_{c}\left(\hat{x}_{0}\right) & =\left[\frac{\partial \hat{x}_{0}}{\partial \hat{b}_{0}}\right]^{2} V\left(\hat{b}_{0}\right)+\left[\frac{\partial \hat{x}_{0}}{\partial \hat{b}_{1}}\right]^{2} v\left(\hat{b}_{1}\right)+\left[\frac{\partial \hat{x}_{0}}{\partial \hat{b}_{2}}\right]^{2} v\left(\hat{b}_{2}\right)+ \\
2 & \frac{\partial \hat{x}_{0}}{\partial \hat{b}_{0}} \frac{\partial \hat{x}_{0}}{\partial \hat{b}_{1}} \operatorname{cov}\left(\hat{b}_{0}, \hat{b}_{1}\right)+2 \frac{\partial \hat{x}_{0}}{\partial \hat{b}_{0}} \frac{\partial \hat{x}_{0}}{\partial \hat{b}_{2}} \operatorname{cov}\left(\hat{b}_{0}, \hat{b}_{2}\right) \\
& +2 \frac{\partial \hat{x}_{0}}{\partial \hat{b}_{1}} \frac{\partial \hat{x}_{0}}{\partial \hat{b}_{2}} \operatorname{cov}\left(\hat{b}_{1}, \hat{b}_{2}\right)
\end{aligned}
$$

where $\operatorname{Cov}()$ denotes the covariance between two parameters. The random variance for $\hat{\mathrm{x}}_{0}$, $\mathrm{V}_{\mathrm{r}}\left(\hat{\mathrm{X}}_{0}\right)$, is given by

$$
V_{I}\left(\hat{X}_{o}\right)=\left[\frac{\partial \hat{X}_{0}}{\partial e}\right]^{2} V(e)=\left[\frac{\partial \hat{X}_{0}}{\partial e}\right]^{2} \partial_{\theta}^{2}
$$

The notation of Reference 5 , is used to define the quantity

$$
S_{X Y}=\sum_{i=1}^{n}\left(X_{i}-\bar{X}\right)\left(Y_{i}-\bar{Y}\right)
$$

where over-bars indicate average values, and $X_{i}$ and $Y_{i}$ are the $X$ and $Y$ coordinates of the data for $i$ equals 1 to $n$ data pairs. The 
variance of the model error term, $V(e)$ is defined as

$$
V(e)=\partial_{\theta}^{2}=\sum_{i=1}^{n}\left(Y_{i}-\hat{Y}_{i}\right)^{2} / d f
$$

where df is the degrees of freedom for the regression which is equal to $n$ minus the number of parameters in the model.

\section{Application to Linear Models}

For the general linear model with nonzero intercept, $\hat{b}_{2}$ is not included in the model and the coefficients $\hat{b}_{1}$ and $\hat{b}_{0}$ are given by

$$
\hat{b}_{1}=s_{X Y} / s_{X X X}, \quad b_{0}=\bar{Y}-b_{1} \bar{X}
$$

For a linear model without a $Y$-intercept term, $\hat{b}_{Q}$ is forced to be zero. In this model, $b_{1}$ is calculated using

$$
\hat{b}_{1}=\sum_{1=1}^{n} X_{1} Y_{1} / \sum_{i=1}^{n} X_{1}^{2}
$$

The variance and covariance terms for the general linear model are given by ${ }^{5}$

$$
\begin{gathered}
V\left(\hat{b}_{0}\right)=\frac{\hat{\partial}_{\theta}^{2} \sum_{i=1}^{n} x_{1}^{2}}{n S_{x x}}, \quad V\left(b_{1}\right)=\frac{\partial_{\theta}^{2}}{S_{x x}} \\
\operatorname{Cov}\left(\hat{b}_{0}, \hat{b}_{1}\right)=-\bar{X} \bar{\partial}_{\theta}^{2} / s_{x x}
\end{gathered}
$$

and for the forced zero-intercept model, $\mathrm{V}\left(\hat{\mathrm{b}}_{1}\right)$ can be derived to be

$$
V\left(b_{1}\right)=\hat{\sigma}_{e}^{2} / \sum_{i=1}^{n} X_{1}^{2}
$$

The partial derivatives needed to calculate $\mathrm{V}_{\mathrm{c}}\left(\hat{\mathrm{X}}_{\mathrm{o}}\right)$ and $\mathrm{V}_{\mathrm{r}}\left(\hat{\mathrm{X}}_{0}\right)$ are

$$
\frac{\partial \hat{X}_{0}}{\partial \hat{b}_{0}}=\frac{-1}{\hat{b}_{1}}, \frac{\partial \hat{X}_{0}}{\partial \hat{b}_{1}}=\frac{-\left(Y_{0}-\hat{b}_{0}-e\right)}{\hat{b}_{1}^{2}}, \frac{\partial \hat{X}_{0}}{\partial \hat{e}}=\frac{-1}{\hat{b}_{1}}
$$

Using the partial derivatives, $V_{c}\left(\hat{x}_{o}\right)$ and $\mathrm{V}_{\mathrm{r}}\left(\hat{\mathrm{X}}_{\mathrm{o}}\right)$ are given by

$$
\begin{gathered}
V_{c}\left(\hat{f}_{0}\right)=\frac{1}{\hat{b}_{1}^{2}} V\left(\hat{b}_{0}\right)+\frac{\left(Y_{0}-\hat{b}_{0}-e\right)^{2}}{\hat{b}_{1}^{4}} V\left(\hat{b}_{1}\right) \\
+2 \frac{\left(Y_{0}-\hat{b}_{0}-e\right)}{\sigma_{1}^{3}} \operatorname{Cov}\left(\hat{b}_{0}, \hat{b}_{1}\right)
\end{gathered}
$$

$$
V_{x}\left(\hat{X}_{0}\right)=\frac{1}{\hat{G}_{1}{ }^{2}} V(e)=\frac{1}{\hat{b}_{1}{ }^{2}} \partial_{e}^{2}
$$

In application of these equations, the (expected) value of $e$ is zero. For the general linear model, the equations for $V_{c}\left(\hat{X}_{0}\right)$ and $V_{f}\left(\hat{x}_{0}\right)$ are the same as those equations given by Jaech (Ref. 3, Equations 3.26 and 3.28 , respectively). For the forced zero-intercept model, the same equations are used with $\hat{\mathrm{b}}_{0}, \mathrm{~V}\left(\hat{\mathrm{b}}_{0}\right)$ and $\operatorname{Cov}\left(\hat{b}_{0}, \hat{b}_{1}\right)$ equal to zero.

\section{Application to a Quadratic Model}

For regression models higher than first order, the algebraic expressions for the regression coefficients and their variances are more complicated and will not be presented here. It is assumed that these values can be obtained from the multiple regression software used to analyze the data. To generate the covariance terms needed from the Pearson correlation coefficients generated by some software packages, the following relationship was used:

$$
\operatorname{Cov}\left(\hat{b}_{j}, \hat{b}_{k}\right)=\sqrt{V\left(\hat{b}_{j}\right) V\left(\hat{b}_{k}\right)} \times \operatorname{Pearson}\left(\hat{b}_{j}, \hat{b}_{k}\right)^{20}
$$

where Pearson $\left(\hat{b}_{j}, \hat{b}_{k}\right)$ is the Pearson correlation coefficient for parameters $\hat{b}_{j}$ and $\hat{\mathrm{b}}_{\mathrm{k}}$.

For the quadratic model,

$$
\frac{\partial \AA_{0}}{\partial \hat{e}}=\frac{ \pm \frac{1}{2}\left(-4 \hat{b}_{2}\right)}{2 \hat{b}_{2} \sqrt{R}}=-\frac{ \pm 1}{\sqrt{R}}
$$

and $V_{r}\left(\hat{x}_{0}\right)$ is given as

$$
V_{I}\left(\hat{X}_{0}\right)=\left[\frac{\partial \hat{X}_{0}}{\partial e}\right]^{2} V(e)=\left[\frac{ - \pm 1}{\sqrt{R}-}\right]^{2} \partial_{e}^{2}=\frac{1}{R} \partial_{e}^{2}
$$

The partial derivatives needed to calculate $\mathrm{V}_{c}\left(\hat{\mathrm{X}}_{\mathrm{o}}\right)$ are

$$
\frac{\partial \hat{X}_{0}}{\partial G_{0}}=\frac{ \pm \frac{1}{2}\left(-4 G_{2}\right)}{2 G_{2} \sqrt{R}}=-\frac{ \pm 1}{\sqrt{R}}
$$

$$
\frac{\partial \hat{A}_{0}}{\partial \hat{b}_{1}}=\frac{-1}{2 \hat{b}_{2}}+\frac{ \pm \frac{1}{2}\left(2 \hat{G}_{1}\right)}{2 \hat{G}_{2} \sqrt{R}}=\frac{1}{2 G_{2} \sqrt{R}}\left(-\sqrt{R} \pm b_{1}\right)
$$

Some other terms needed to calculate $V_{c}\left(\hat{X}_{o}\right)$ are

To calculate $\mathrm{V}_{\mathrm{c}}\left(\mathrm{x}_{\mathrm{o}}\right)$, the correct root of 


$$
\begin{gathered}
\frac{\partial \hat{X}_{o}}{\partial \hat{b}_{2}}=-\frac{-\hat{b}_{1} \pm \sqrt{R}}{2 \hat{b}_{2}^{2}}+\frac{ \pm \frac{1}{2}\left[-4\left(\hat{b}_{0}-Y_{0}+e\right)\right]}{2 \hat{b}_{2} \sqrt{R}} \text { (25) } \\
=\frac{1}{2 \hat{b}_{2}^{2} \sqrt{R}}\left[\hat{b}_{1} \sqrt{R}-\frac{ \pm 1}{2}\left(R+\hat{b}_{1}^{2}\right)\right] \\
{\left[\frac{\partial \hat{X}_{o}}{\partial \hat{b}_{0}}\right]^{2}=\frac{1}{R^{\prime}} \quad\left[\frac{\partial \hat{x}_{o}}{\partial \hat{b}_{1}}\right]^{2}=\frac{1}{4 \hat{b}_{2}^{2} R}\left(-\sqrt{R} \pm \hat{b}_{1}\right)^{2}} \\
\text { (26) }
\end{gathered}
$$
calculated using

$$
\sigma_{1 n v}\left(\hat{X}_{o}\right)=\sqrt{V_{c}\left(\hat{X}_{o}\right)+V_{I}\left(\hat{X}_{o}\right)}
$$




\section{IN-BED ACCOUNTABILITY OF TRITIUM IN PRODUCTION SCALE METAL HYDRIDE STORAGE BEDS}

Presented at the Fifth Topical Meeting on TritiumTechnology in Fission, Fusion and Isotopic Applications

Lake Maggiore, Italy

May 28-June 3, 1995

James. E. Klein 


\section{OUTLINE}

- Background

- Cold Experimental Program Results

- Tritium Bed Calibration Results

- Conclusions 


\section{CURRENT VERSUS RTF TRITIUM PROCESS}

Old Tritium Facilities

(Conventional Technology)

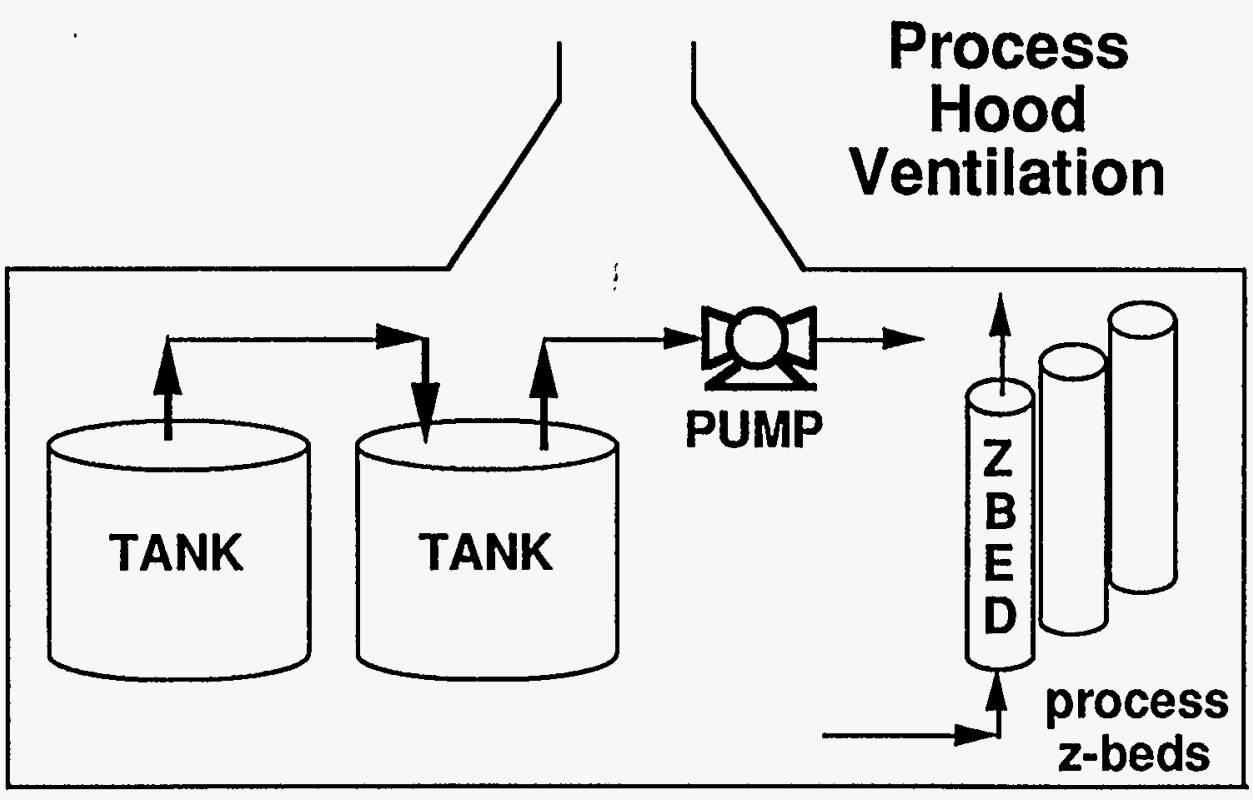

RTF - Replacement

Tritium Facility (Hydride Technology)

Glove Box Containment

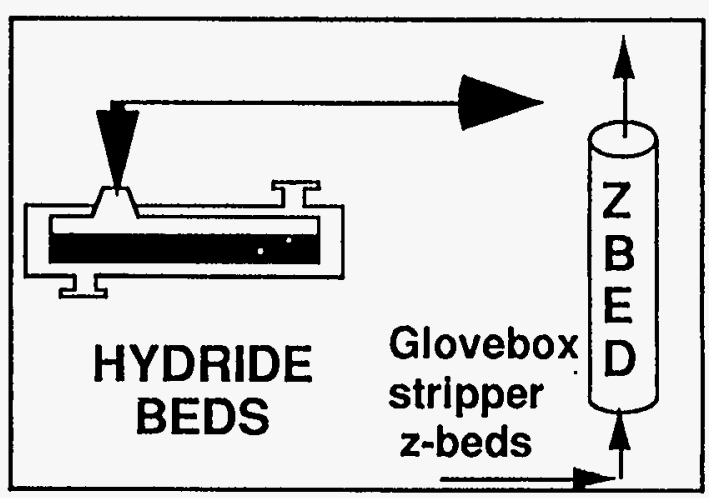




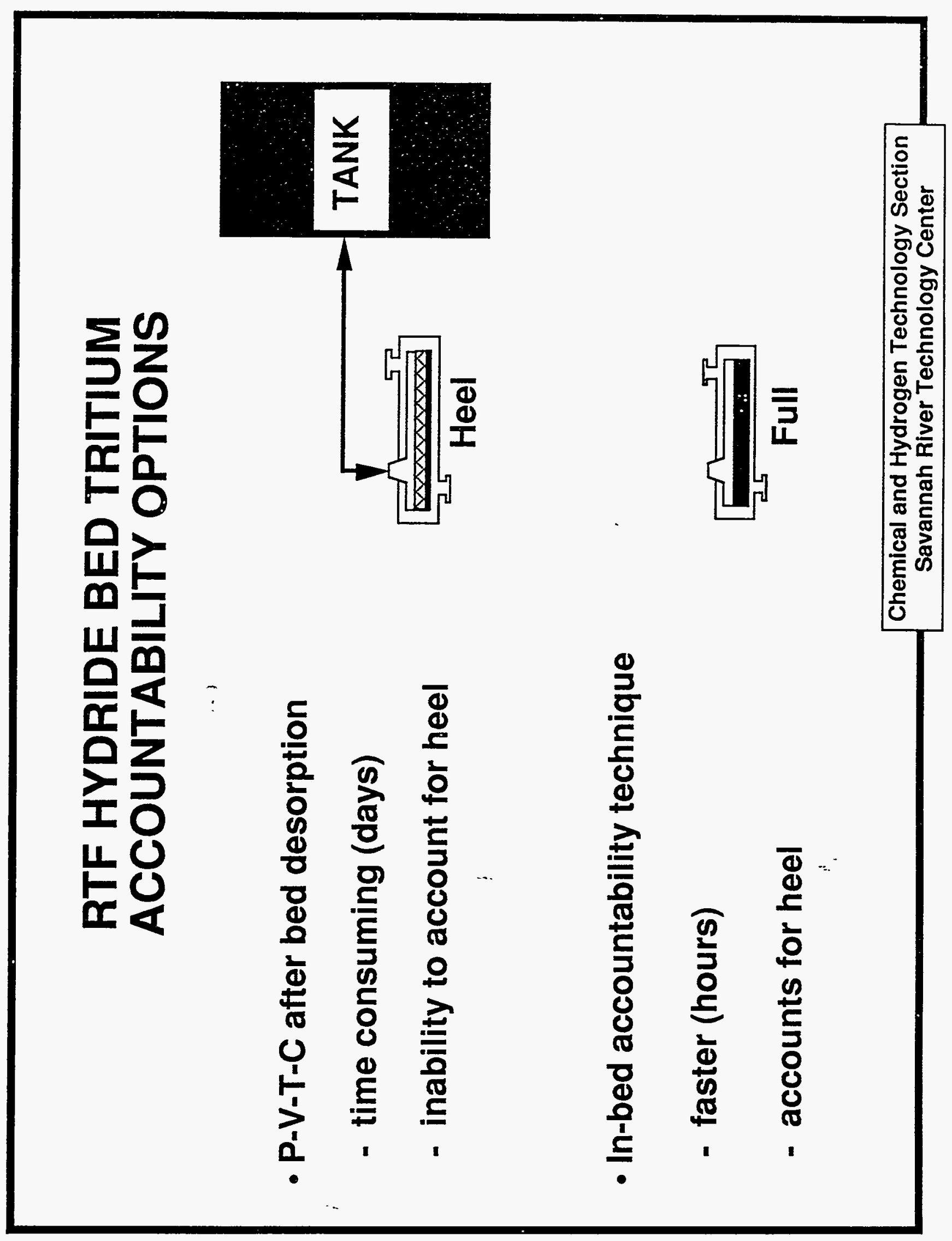




\section{IN-BED ACCOUNTABILITY (IBA) METHOD}

IBA METHOD

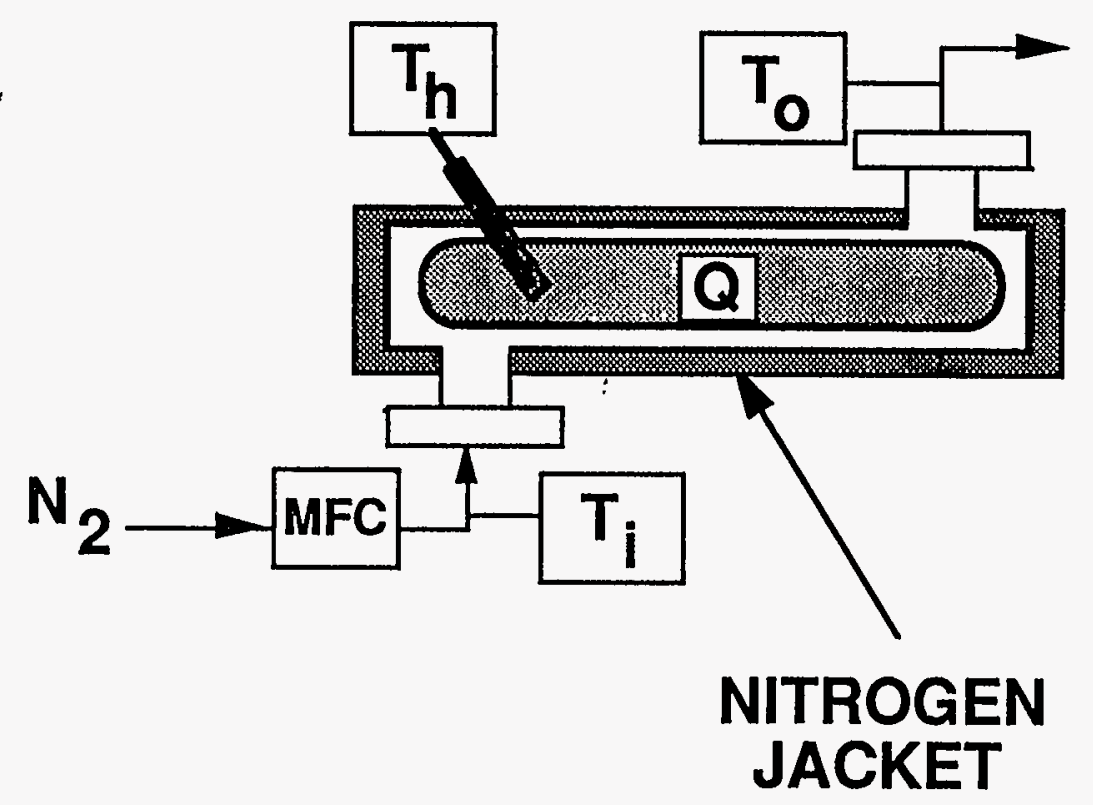

CALIBRATION CURVE

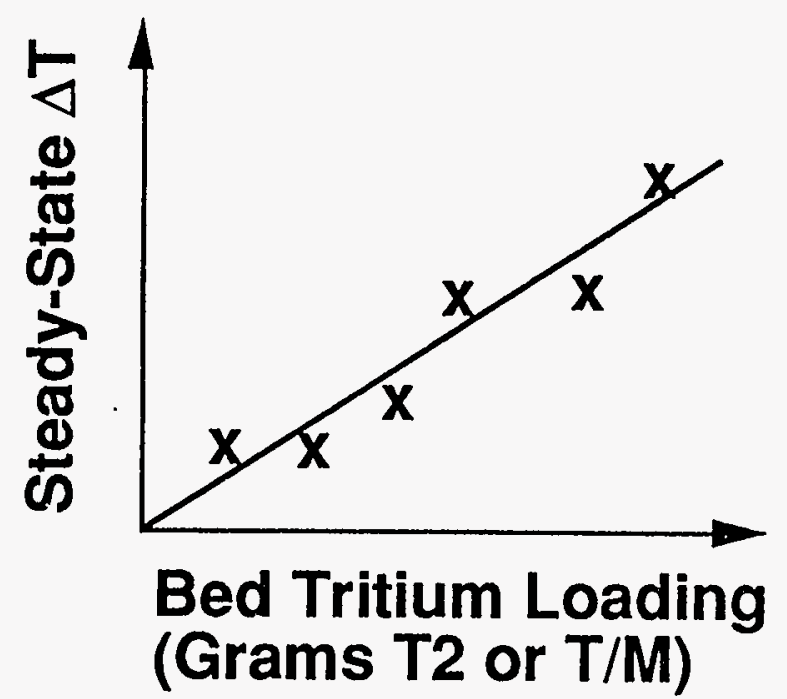

$$
\Delta \mathrm{T}=\mathrm{T}_{\mathbf{0}}-\mathrm{T}_{\mathbf{i}},{ }^{\circ} \mathrm{C},
$$

$T / M=$ Atoms of Tritium to Atoms of Metal Ratio 


\section{COLD TEST APPARATUS}




\section{COLD TEST RESULTS}

- Calibration Curve Different for Each Bed

- Inverse Regression Equations Developed for Quad. Model

- Steady-State (SS) $\Delta T$ Independent of Gas Composition

- Cold Bed (CB) Data Used to Determine Number of Calibration Points (N) Needed for Tritium Bed (TB) Calibrations

- Pick sub-sets of one cold test data set $\left(\mathrm{H}_{2} @ 65\right.$ SLPM)

- Perform multiple regressions on data

- Plot IBA error versus $\mathbf{N}$ for optimum $\mathbf{N}$ 


\section{COLD TEST IBA ERROR VERSUS NUMBER OF CALIBATION POINTS}

Results for Cold Bed \#1 (CB \#1) $\mathrm{H}_{2}$ Data @ 65 SLPM

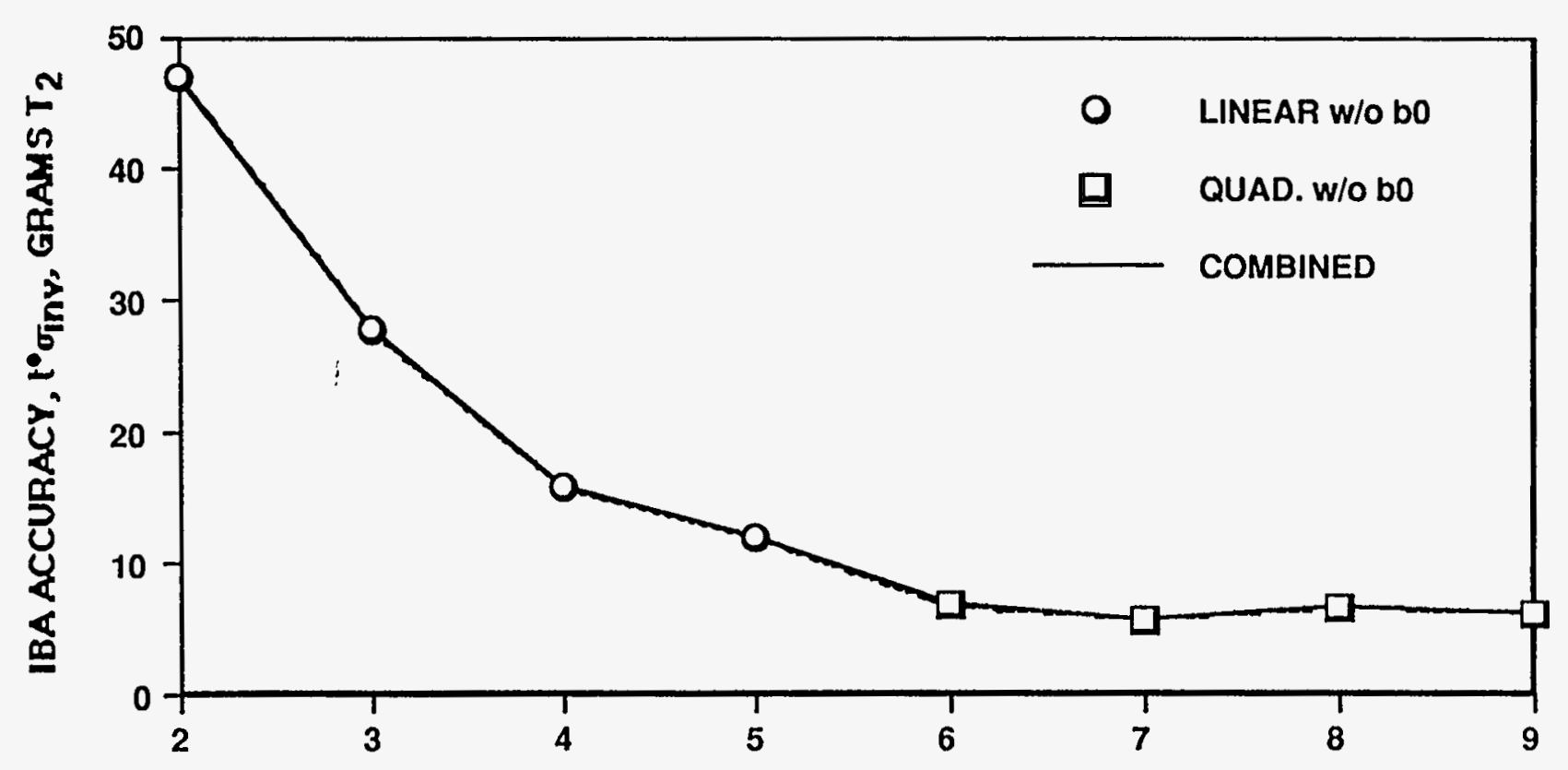

N, NUMBER OF CALIBRATION POINTS 


\section{TRITIUM BED CALIBRATION}

P-V-T-C Bed Loading Equipment

- Calibrated 1500 LiterTank with two RTD probes

- $\pm 93 \mathrm{~Pa}$ (0.7 torr) Pressure Transducer on Tank

- Duplicate Mass Spectrometer Samples

IBA Procedure

- Evacuate Heated Hydride Bed

- Load Tritium from Tank to Bed's Highest Loading

- Record Steady-State $\Delta \mathrm{T}$

- Desorb Fraction of Bed Tritium to Tank

- Repeat Last Two Steps for Other Bed Loadings 


\section{IBA CALIBRATION CURVES}

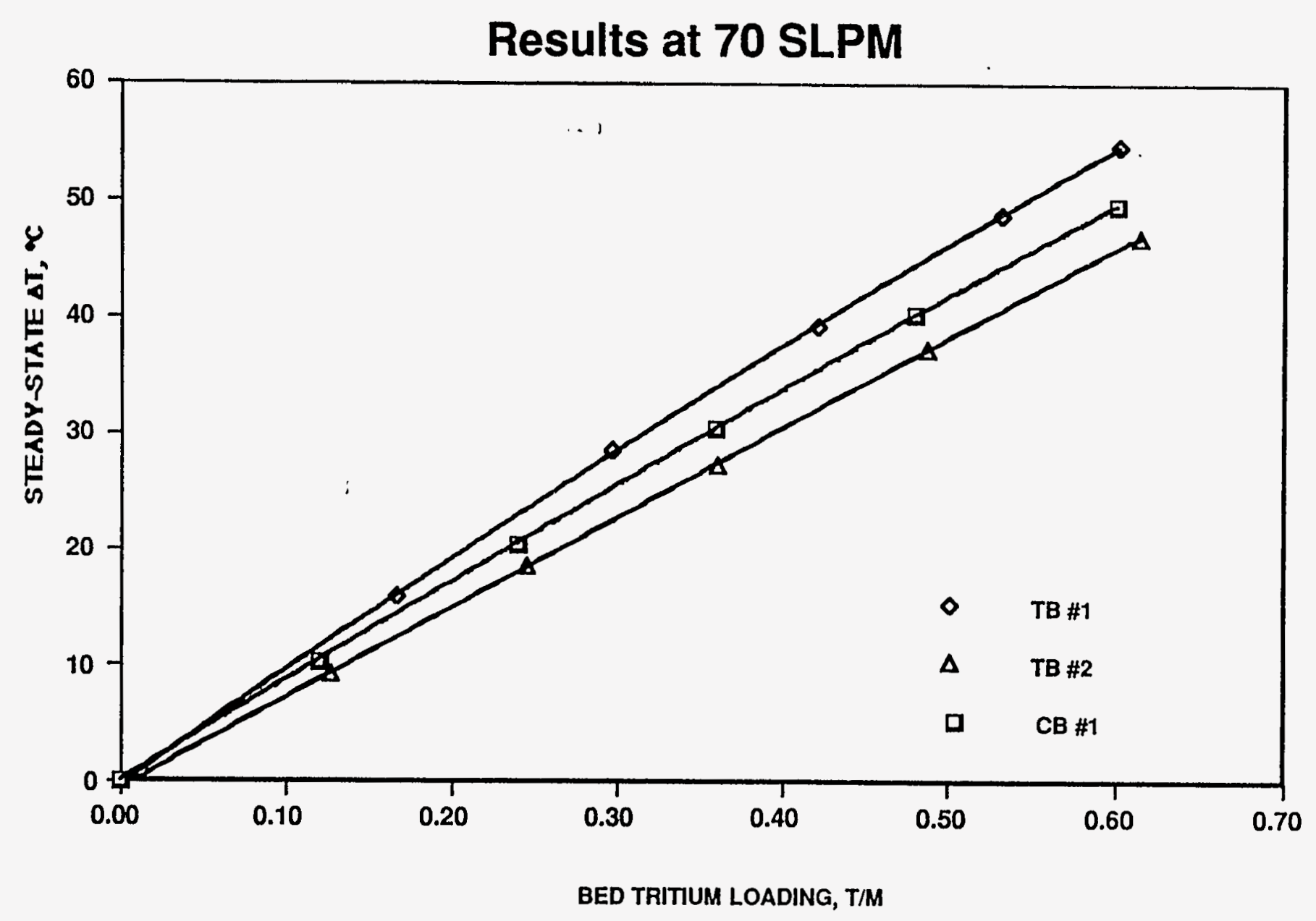




\section{IBA HYDRIDE TEMPERATURE CORRELATION}

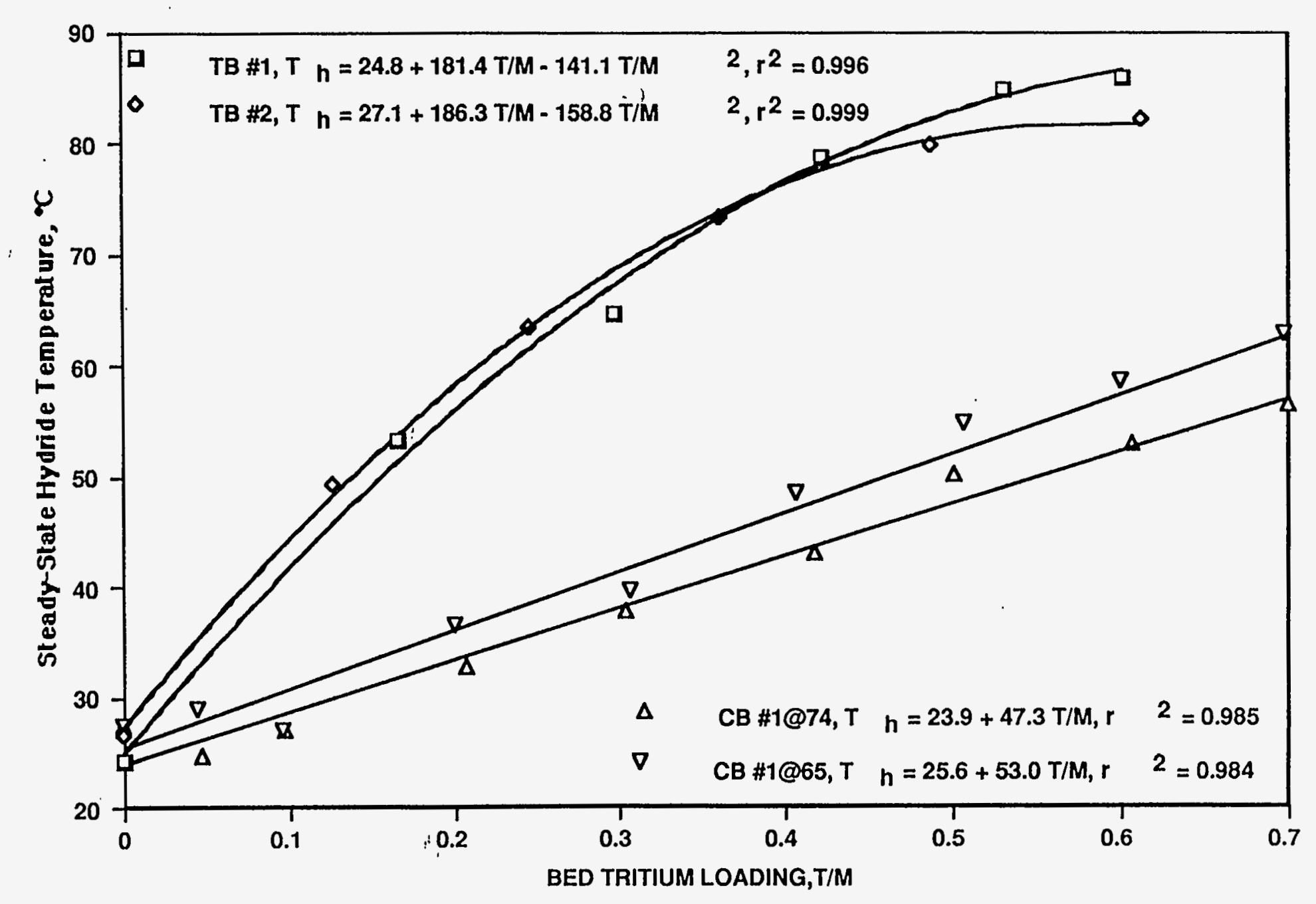

Chemical and Hydrogen Technology Section Savannah River Technology Center 


\section{IBA ERRORS FOR DIFFERENT MODELSa}

$\underline{t}^{*} \sigma_{\text {inv }}$ IBA Inventory Errors $\left(g T_{2}\right)$

Linear Linear Quad. Quad.

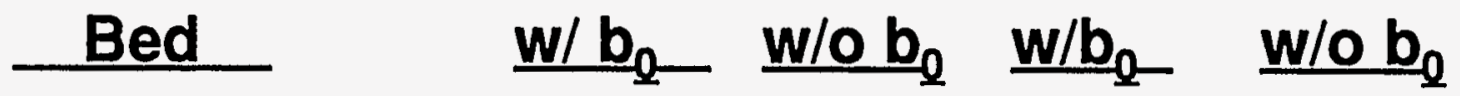

$\begin{array}{lllll}C B \# 1 & 8.98^{\circ} & \underline{7.30} 0^{c} & 8.11^{c} & 7.68^{\circ}\end{array}$

65 SLPM

$\begin{array}{lllll}\mathrm{CB} \# 1 & 13.29^{\mathrm{c}} & 12.31^{\mathrm{c}} & \underline{7.08}^{\mathrm{c}} & \text { 8.60) }\end{array}$

74 SLPM

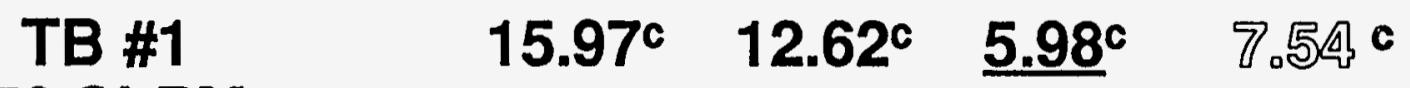

70 SLPM

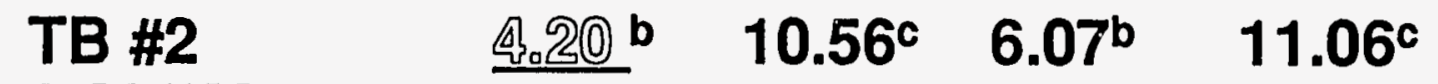

70 SLPM

aMinimum values underlined, "best" model values in "outline" font. bMaximum error at $0.0 \mathrm{~T} / \mathrm{M}$. cMaximum error at $0.7 \mathrm{~T} / \mathrm{M}$. 


\section{CONCLUSIONS}

- Cold Test IBA Results

- Gave results similar to tritium beds

- Useful for estimating number of calibration points needed

Tritium Bed Results

- Excellent calibration curves obtained (63,75\% efficiency)

- Hydride temperatures at SS $\Delta \mathrm{T}$ different than cold tests

Regression Model Selection is Important

- Smaller IBA error possible with quadratic model

- Selecting significant model gives correct IBA errors 


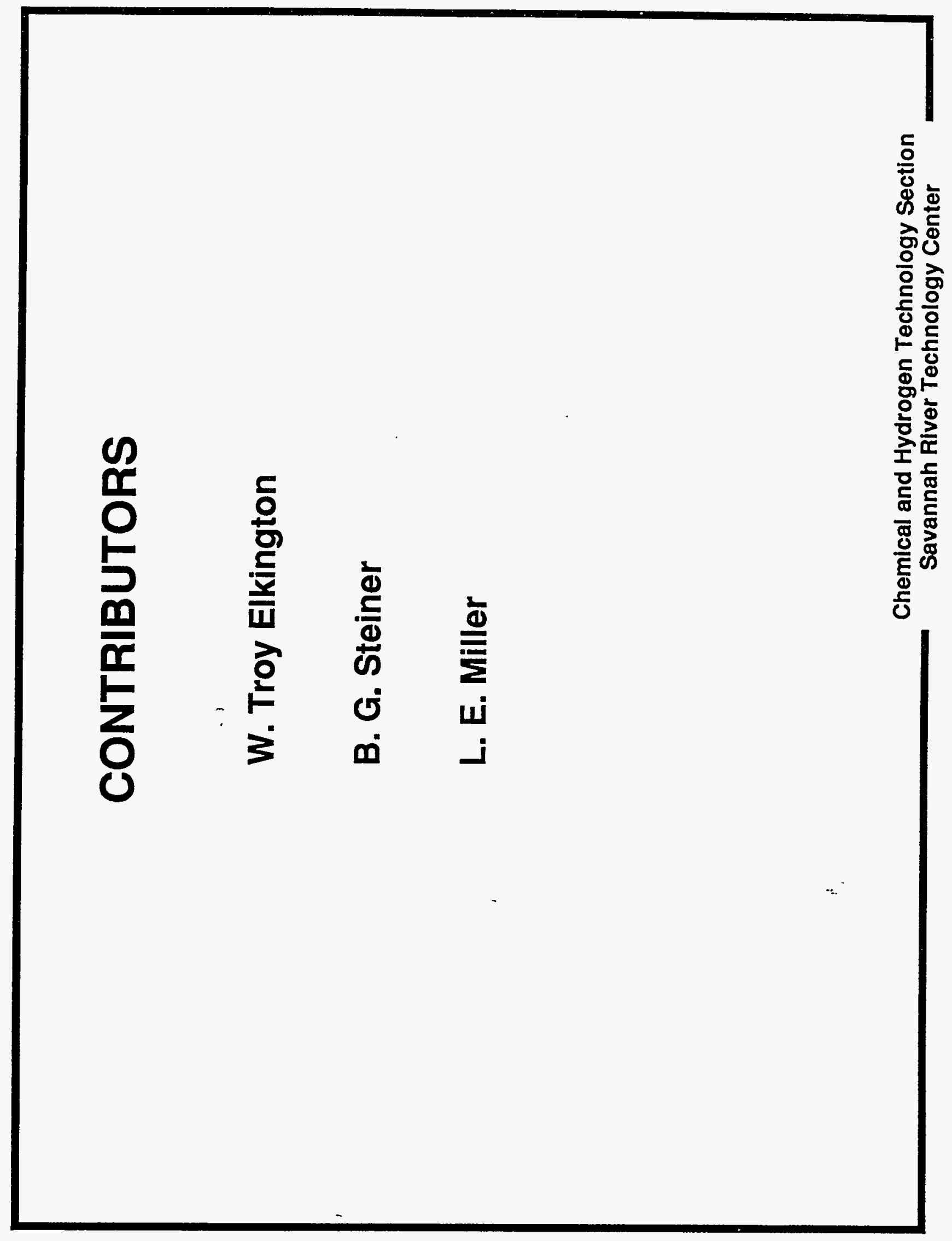

